\title{
Alginate Microparticles as Novel Carrier for Oral Insulin Delivery
}

\author{
Catarina Pinto Reis, ${ }^{1}$ António J. Ribeiro, ${ }^{2}$ Ronald J. Neufeld, ${ }^{3}$ Francisco Veiga ${ }^{1}$ \\ ${ }^{1}$ Laboratory of Pharmaceutical Technology, Faculty of Pharmacy, University of Coimbra, \\ Coimbra, Portugal \\ ${ }^{2}$ Laboratory of Pharmaceutical Technology, North Health Sciences Superior Institute, \\ Gandra, Paredes, Portugal \\ ${ }^{3}$ Chemical Engineering Department, Queen's University, Kingston, Ontario, \\ Canada K7L3N6; telephone: 1-613-2765; fax: 1-613-533-6637; \\ e-mail: ron.neufeld@chee.queensu.ca \\ Received 12 May 2006; accepted 2 August 2006 \\ Published online 25 September 2006 in Wiley InterScience (www.interscience.wiley.com). DOI 10.1002/bit.21164
}

\begin{abstract}
Alginate microparticles produced by emulsification/internal gelation were investigated as a promising carrier for insulin delivery. The procedure involves the dispersion of alginate solution containing insulin protein, into a water immiscible phase. Gelation is triggered in situ by instantaneous release of ionic calcium from carbonate complex via gentle $\mathrm{pH}$ adjustment. Particle size is controlled through the emulsification parameters, yielding insulinloaded microparticles. Particle recovery was compared using several washing protocols. Recovery strategies are proposed and the influence on particle mean size, morphology, recovery yield (RY), encapsulation efficiency, insulin release profile, and structural integrity of released insulin were evaluated. Spherical micron-sized particles loaded with insulin were produced. The recovery process was optimized, improving yield, and ensuring removal of residual oil from the particle surface. The optimum recovery strategy consisted in successive washing with a mixture of acetone/ hexane/isopropanol coupled with centrifugation. This strategy led to small spherical particles with an encapsulation efficiency of $80 \%$ and a RY around $70 \%$. In vitro release studies showed that alginate itself was not able to suppress insulin release in acidic media; however, this strategy preserves the secondary structure of insulin. Particles had a mean size lower than the critical diameter necessary to be orally absorbed through the intestinal mucosa followed by their passage to systemic circulation and thus can be considered as a promising technology for insulin delivery. Biotechnol. Bioeng. 2007;96: 977-989.
\end{abstract}

(C) 2006 Wiley Periodicals, Inc.

KEYWORDS: alginate; emulsification/internal gelation; microparticles; insulin; recovery process

\section{Introduction}

The challenge of administering insulin orally has been addressed over the last several decades with a view to helping ease the pain and stress caused during insulin injections by the millions of diabetic patients worldwide. Insulin is a peptide drug and for this reason is still a challenge for oral dosage, due to enzymatic and/or metabolic degradation in the gastrointestinal tract.

Much research has been conducted to find an ideal oral insulin delivery system that mimics the physiologic pattern of insulin secretion (Carino et al., 2000). To ensure enteric protection, recent advances in pharmaceutical technology have led to a growth of innovative formulations such as liposomes (Takeuchi et al., 1996), microparticles (Morishita et al., 2004), and nanoparticles (Ma et al., 2005; Mesiha et al., 2005). In drug delivery, nanoparticles have demonstrated numerous advantages over conventional formulations (Sakuma et al., 2001; Soppimath et al., 2001); however, most techniques for producing small particles involve the use of organic solvents, heat or vigorous agitation which are potentially harmful to the structure and consequently biological activity of proteins (Tiyaboonchai et al., 2003). In this study, we describe small microparticles produced under mild processing conditions by using emulsification/internal gelation technology that has previously been only applied to the production of larger sized microparticles (Alexakis et al., 1995; Poncelet et al., 1992; Quong et al., 1998; Ribeiro et al., 1999). This methodology was substantially modified to produce micron- and nanometer-sized particles (Reis et al., 2006).

Correspondence to: R.J. Neufeld

Contract grant sponsor: Fundação para a Ciência e Tecnologia, Portugal

Contract grant sponsor: Natural Sciences and Engineering Research Council of Canada

Contract grant number: SFRH/BD/13673/2003

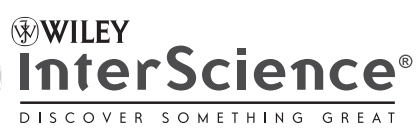


The main difficulty in obtaining micro- and nanoparticles by emulsification methods is related to the recovery of oildispersed particles due to the high stability of the resultant dispersion and due to the difficulty in completely eliminating residual oil. Recovery of the particles produced by emulsification-based methods depends largely on the size of the particles. Relatively large and rigid particles are readily separated from the dispersion by filtration or decantation (Arshady, 1990) but as the particle size decreases, the separation problems are magnified (Magenheim and Benita, 1991). Generally, particles smaller than $10 \mu \mathrm{m}$ are recovered by centrifugation (Arshady, 1990).

The aim of this study was to produce small-sized alginate microparticles by emulsification/internal gelation with a mean diameter less than $10 \mu \mathrm{m}$ for potential oral insulin delivery. The absorption of particles from the intestine is affected by a number of factors amongst which particle size is prominent (Saez et al., 2000). The critical particle size to enable absorption is still the subject of some debate (Norris et al., 1998) but generally $10 \mu \mathrm{m}$ appears as upper limit (Cho et al., 1998). An additional consideration for intestinal transport is the charge carried by the molecule. Due to a predominance of negatively charged groups around the intestinal pores (negative sialic acid groups on mucin), neutral or cationic compounds should pass more easily through these paracellular aqueous pores compared to anionic compounds. A discrepancy, however, is observed since the negatively charged guluronic acid of alginate also appears to interact with the mucin (Cho et al., 1998; Norris et al., 1998).

The detailed methodology to produce small-sized alginate microparticles is described and the effect of particle recovery procedure on mean size, particle morphology, recovery yield (RY), encapsulation efficiency of insulin, insulin release profile, and structural stability of insulin is reported. This methodology uses alginate as encapsulation matrix. Compared to other polymers, alginate offers additional advantages in terms of safety and biodegradability, biocompatibility, availability, and low cost and thus serves as an excellent candidate for the development of oral insulin formulation.

\section{Materials and methods}

\section{Materials}

Medium viscosity sodium alginate (approximately 300-500 cps at $1 \% \mathrm{w} / \mathrm{v}, 25^{\circ} \mathrm{C}$ ) extracted from Laminaria hyperborea, Algogel $3541^{\circledR}$, was supplied by Degussa Texturant Systems France SAS (Boulogne Billancourt Cedex, France). Ultrafine calcium carbonate (Setacarb 06, Omya, Orgon, France), paraffin oil (low viscosity mineral oil from Fischer Chemicals, Fair Lawn, NJ) and Span 80 (sorbitan monooleate from Fluka, Biochemika, Steinheim, Germany) were used in the procedure. Human insulin was of recombinant DNA origin (Insulin Actrapid A/S ${ }^{\circledR} 100 \mathrm{IU}: 3.5 \mathrm{mg} / \mathrm{mL}$ ) supplied by Novo Nordisk A/S, Bagsværd, Denmark. All other chemicals used were of reagent analytical grade.

\section{Methods}

\section{Preparation of Small-Sized Alginate Microparticles}

The emulsification-internal gelation technique to form alginate gel microbeads as described previously (Poncelet, 2001; Poncelet et al., 1999, 1992, 1995; Quong et al., 1998; Ribeiro et al., 1999) was modified to form alginate particles ranging from a few microns into the nano-size range. An aqueous dispersion of insoluble, ultrafine calcium carbonate crystals $(5 \%, \mathrm{w} / \mathrm{v})$ was sonicated for $30 \mathrm{~min}$ to break up crystal aggregates. Then, $8.3 \mathrm{~mL}$ of calcium carbonate suspension were suspended in an aqueous solution $(50 \mathrm{~mL})$ of alginate $(2 \%, \mathrm{w} / \mathrm{v})$ containing insulin $(35 \mathrm{mg})$. After homogenization, the resulting dispersion was emulsified within paraffin oil (aqueous phase/oil phase 50/50, v/v) containing $1.5 \mathrm{~mL}$ of Span 80 by impeller-stirring homogenization (1,600 rpm). After $15 \mathrm{~min}$ emulsification, $20 \mathrm{~mL}$ of paraffin oil containing glacial acetic acid (molar ratio acid-calcium, 3.5) were added to the dispersion and stirring continued for $60 \mathrm{~min}$ to trigger instantaneous solubilization of calcium from carbonate complex and concomitant gelation of the alginate particles. Insulin-free particles were also prepared using the same procedure. Each batch was prepared in duplicate.

\section{Particle Recovery}

Oil-dispersed alginate particles were recovered by several optimized washing protocols namely A, B, and C as described in Table I. Briefly, $100 \mathrm{~mL}$ of acetate buffer solution at $\mathrm{pH} 4.5$ were added to the biphasic-system followed by agitation on an orbital shaker (100 rpm, $10 \mathrm{~min})$. Aqueous-dispersed particles were separated by decantation and the remaining biphasic-dispersed particles were separated by centrifugation $(12,500-80,000 \mathrm{~g} / 30 \mathrm{~min}$, protocol A). Alternatively, particle recovery was achieved by using the lowest centrifugation rate $(12,500 \mathrm{~g})$ and different volume ratios of dehydrating solvents with acetate buffer instead of $100 \mathrm{~mL}$ of only acetate buffer. These protocols were designated as B1, B2, B3, and B4 as described in Table I.

Table I. Composition of optimized recovery media to isolate microparticles.

\begin{tabular}{llc}
\hline Protocol & \multicolumn{1}{c}{ Composition } & $\%$ (Volume) \\
\hline A & ABS & 100 \\
B1 & Acetone and ABS & $40: 60$ \\
B2 & Acetone, isopropanol, Tween 80, and ABS & $30: 10: 1: 59$ \\
B3 & Acetone, isopropanol, hexane, and ABS & $15: 10: 5: 70$ \\
B4 & Acetone, isopropanol, ether petroleum, and ABS & $15: 10: 5: 70$ \\
C & ABS containing $\mathrm{CaCl}_{2}$ at 50 mM and Tween 80 & $99: 1$ \\
\hline
\end{tabular}

A total volume of $100 \mathrm{~mL}$ was used in all protocols (ABS means acetate buffer solution at $\mathrm{pH} 4.5$-USP XXVIII). 
Finally, particle recovery was also achieved by using the lowest centrifugation rate $(12,500 \mathrm{~g})$ and acetate buffer containing calcium chloride with Tween 80 and this protocol was classified as protocol C. For all protocols, the final volume of washing media was constant, $100 \mathrm{~mL}$.

After recovery, particles were re-suspended in acetate buffer at $\mathrm{pH} 4.5$ and stored at $4^{\circ} \mathrm{C}$. Alternatively, particles were frozen and lyophilized at $0^{\circ} \mathrm{C}$ for at least $48 \mathrm{~h}$. After lyophilization, particles were stored at $4^{\circ} \mathrm{C}$.

\section{Removal of Residual Oil From Particles}

During recovery, small aliquots of particles were taken after each washing cycle and observed under optical microscope (Olympus BH2-UMA) equipped with a Cue-2 image analyzer (Olympus, Tokyo, Japan) to monitor for the presence of oil film. The efficacy of the recovery procedures was evaluated by the number of washing cycles to ensure a complete removal of oil from the particle surface. This assay was performed using insulin-free wet particles.

\section{Recovery Yield}

RY was assessed by measuring the ratio between the recovered lyophilized particles and the initial mass of solids according to Equation (1).

$$
\mathrm{RY}(\%)=\frac{\text { Weight of particles recovered }}{\text { Initial mass }} \times 100
$$

${ }^{*}$ Mass of alginate, insulin plus calcium carbonate.

\section{Particle Morphology}

Mean size was determined by laser diffraction spectroscopy (LDS) using a Coulter LS130 granulometer. Measurements were made in triplicate on dilute insulin-loaded alginate particle suspensions in acetate buffer solution at $\mathrm{pH}$ 4.5. The refraction index applied was the Fraunhofer model. The shape, surface characteristics, and size of the alginate particles were also characterized using scanning electron microscopy, SEM (JSM-840, JEOL Instruments, Tokyo, Japan). Wet particles were deposited on metal grids using double-faced adhesive and coated with gold before observation.

\section{Insulin Encapsulation Efficiency}

Encapsulation efficiency using alginate as the main polymer is generally determined after gel network dissolution with a chelator such as sodium citrate (Ribeiro et al., 1999). However, in order to perform a preliminary test of this formulation as potential for oral insulin delivery, this assay was performed in triplicate under simulated gastric and intestinal conditions without enzymes. Ten milligrams of lyophilized insulin-loaded particles were incubated in $10 \mathrm{~mL}$ hydrochloric acid buffer at pH 1.2 (USP XXVIII) under magnetic stirring (100 rpm, $2 \mathrm{~h}$ ). Aliquots of $1.5 \mathrm{~mL}$ were collected and centrifuged. The supernatant containing released insulin was collected to be assayed. The remaining insulin-loaded alginate particles were transferred into a phosphate buffer at $\mathrm{pH} 6.8$ (USP XXVIII) under magnetic stirring (100 rpm, $1 \mathrm{~h}$ ). Aliquots of $1.5 \mathrm{~mL}$ were collected, centrifuged, and the supernatant containing released insulin was collected for protein quantification by spectrophotometry (Cary $1{ }^{\circledR}$, Varian, Australia) at $595 \mathrm{~nm}$ with the Bradford modified method using Coomassie plus kit (Pierce, Fisher Canada). The encapsulation efficiency (EE) of insulin was then calculated according to Equation (2), assuming that all insulin encapsulated was released during $3 \mathrm{~h}$ :

$$
\mathrm{EE}(\%)=\frac{\text { Total mass insulin released }(\mathrm{pH} 1.2+6.8)}{\text { Initial mass insulin }} \times 100
$$

\section{Release Studies}

To characterize the $\mathrm{pH}$-dependent insulin release profiles of alginate particles under simulated gastrointestinal conditions, known amounts of particles $(10 \mathrm{mg})$ were incubated following above conditions. Samples at appropriate intervals were withdrawn and assayed for protein. An equal volume of the hydrochloric acid buffer at $\mathrm{pH} 1.2$ was added to maintain a constant volume. Release was monitored for $2 \mathrm{~h}$. To simulate the progress of alginate particles moving from the stomach into the upper small intestine, the buffer was changed after $1 \mathrm{~h}$ to higher $\mathrm{pH}(\mathrm{pH}$ 6.8 ), and samples were collected and protein was assayed. The cumulative insulin release was calculated according to Equation (3):

$$
\mathrm{CR}=\frac{\left(C n \cdot V+V_{\mathrm{i}} \sum_{T_{\mathrm{i}}=0}^{T_{\mathrm{n}}-1} C_{\mathrm{i}}\right)}{W \cdot \text { Drug Content }} \times 100
$$

where $C n$ is the sample concentration at $T n$; $V$, the total volume of release medium; $V_{\mathrm{i}}$, the sampling volume at $T_{\mathrm{i}} ; C_{\mathrm{i}}$, the sample concentration at $T_{\mathrm{i}}$ (both $V_{\mathrm{o}}$ and $C_{\mathrm{o}}$ were equal to zero), and $W$ the weight of lyophilized particles used for drug content determination.

To deliver insulin for a long time, the original conformation of insulin must be maintained throughout the whole delivery period. Reversed-phase high-performance liquid chromatography (RP-HPLC)/HPLC mass and circular dichroism (CD) were employed to determine structural/conformational changes of insulin.

\section{RP-HPLC and HPLC-Mass}

HPLC is a sensitive assay, able to detect a single peptide bond cleavage. A HPLC system (model HP1100 series, 
Hewlett Packard, Waldbronn, Germany) equipped with autosampler (Agilent 1100 series, Germany), C18 column (5 $\mu \mathrm{m}, 250 \mathrm{~mm} \times 4.6 \mathrm{~mm}$ i.d.; Waters Corporation, Milford, MA) with a Purospher ${ }^{\circledR}$ STAR RP-18 (precolumn, $5 \mu \mathrm{m}, 4 \mathrm{~mm} \times 4 \mathrm{~mm}$, Merck KGaA, Darmstadt, Germany) was used to examine insulin aggregation. The mobile phase was water (solution A) and acetonitrile (solution B) with $0.04 \%$ trifluoroacetic acid at a flow rate of $1.2 \mathrm{~mL} / \mathrm{min}$. A linear gradient of $30 \%-40 \%$ B over 5 min was used. Insulin solution $(20 \mu \mathrm{L})$ was injected and eluted over $12 \mathrm{~min}$. The absorbance of the eluant was recorded at $210 \mathrm{~nm}$, and the area under the curve was measured for calculation of insulin concentration based on the calibration curves. Insulin samples for HPLC analysis were prepared by dissolution in citrate sodium $55 \mathrm{mM}$ prior to analysis. For HPLC-MS analysis, previous samples were then analyzed using an Surveyor HPLC system (Thermofinnigan, San Jose, CA) with degasser, quaternary pump, autosampler, column oven (all from Thermofinnigan), and diode array detector (LCQ Advantage, Thermofinnigan). A linear gradient of $30 \%-50 \%$ solvent B (acetonitrile $+0.04 \% \mathrm{v} / \mathrm{v}$ TFA) in solvent A (double-distilled water $+0.04 \% \mathrm{v} / \mathrm{v}$ TFA) over 12 min served as a mobile phase. About $10-20 \mu \mathrm{L}$ of the samples were separated using a C18 reversed phase analytical column (X-Terra MS, Waters, $5 \mu \mathrm{m}, 2.1 \times 250 \mathrm{~mm}$ ). The XCALIBUR software package (Thermofinnigan) was used for data acquisition and analysis.

\section{Circular Dichroism Spectroscopy}

Circular dichroism (CD) spectra were obtained with a Jasco J-720 spectropolarimeter (Tokyo, Japan) equipped with a temperature controller to examine the secondary structure of insulin in particles. Spectra were collected at $25^{\circ} \mathrm{C}$ using a $0.1 \mathrm{~cm}$ cell over the wavelength range of $200-260 \mathrm{~nm}$. A resolution of $0.2 \mathrm{~nm}$ and scanning speed $\left(50 \mathrm{~nm} \mathrm{~min}{ }^{-1}\right.$ ) with a $4 \mathrm{~s}$ response time were employed. Each spectrum obtained represents an average of three consecutive scans. Noise reduction, blank buffer subtraction, and data analysis were performed using standard analysis and temperature/ wavelength analysis programs (Jasco). Samples for CD analysis were prepared by dissolution in isotonic PBS buffer. The spectra of insulin samples with concentrations about $10 \mu \mathrm{M}$ were compared with that of fresh insulin.

\section{Statistical Analysis}

Each value of RY and encapsulation efficiency was presented as mean $\pm \mathrm{SD}$. Multiple comparison between several protocols was analyzed with a one-way layout analysis of variance (ANOVA). Post-test comparisons were performed by the Student-Newman-Keuls method. Statistical analysis was performed with Sigma Stat (version 2.03; SPSS Inc. Chicago, IL). A $P<0.05$ was taken as the criterion of significance.

\section{Results and Discussion}

The objectives of the present study were to produce small-sized insulin-loaded alginate microparticles by emulsification/internal gelation, and to develop a recovery procedure with respect to defined particle morphology and encapsulation efficiency of insulin. Recovery of larger alginate microspheres produced by a similar procedure has been demonstrated by partitioning into a calcium chloride solution containing surfactant (Poncelet, 2001; Ribeiro et al., 1999) but this procedure was ineffective in the recovery of particles less than $10 \mu \mathrm{m}$, required for the present study. For purposes of developing an oral dosage form of insulin, an optimum recovery procedure would be determined by high particle recovery efficiency, production of discrete particles with mean diameter less than $10 \mu \mathrm{m}$, and through high encapsulation efficiency of insulin.

\section{Recovery Efficiency of Particles}

The particle recovery efficiency of the various procedures was evaluated both by its capacity to eliminate residual oil and oil droplets and by RY. Oil-dispersed particles were recovered by a washing step associated with centrifugation. Concerning the efficiency of residual oil removal, protocol A required fewer centrifugation/wash cycles (from 9 to 7 ) when higher centrifugation rates were applied as described in Table II. It was determined that seven wash cycles were adequate to eliminate the residual oil with $55,000-80,000 \mathrm{~g}$ as illustrated microscopically by Figure $1 \mathrm{a}$ and $\mathrm{b}$. No additional benefit was demonstrated with more than seven wash cycles. Protocol $\mathrm{C}$ required the same number of wash cycles as protocol A with $12,500 \mathrm{~g}$, and thus no additional advantage is achieved with this procedure. In contrast, the number of centrifugation cycles coupled with dehydrating solvents was

Table II. Influence of optimized recovery protocols ${ }^{\star}$ on the number of wash cycles, mean size, and morphology of alginate particles.

\begin{tabular}{|c|c|c|c|c|}
\hline Procedures & $\mathrm{g} \times$ force & $\begin{array}{c}\mathrm{N}^{\circ} \text { wash } \\
\text { cycles }\end{array}$ & $\begin{array}{c}\text { Mean } \\
\text { size }(\mu \mathrm{m})\end{array}$ & Morphology \\
\hline A & $\begin{array}{c}12,500 \\
55,000 \text { and } \\
80,000\end{array}$ & $\begin{array}{l}9 \\
7\end{array}$ & $6.02 \pm 1.35$ & $\begin{array}{l}\text { Spherical shape } \\
\text { Smooth surface }\end{array}$ \\
\hline B1 & 12,500 & 6 & $4.65 \pm 1.75$ & $\begin{array}{l}\text { Loss of spherical } \\
\text { shape } \\
\text { Irregular shape } \\
\text { Rough surface }\end{array}$ \\
\hline B2 & 1,2500 & 5 & $5.57 \pm 2.56$ & $\begin{array}{l}\text { Loss of spherical } \\
\text { shape } \\
\text { Irregular shape }\end{array}$ \\
\hline B3 & 12,500 & 4 & $4.18 \pm 0.28$ & $\begin{array}{l}\text { Spherical particles } \\
\text { Rough surface }\end{array}$ \\
\hline B4 & 12,500 & 5 & $68.27 \pm 66.55$ & $\begin{array}{l}\text { Spherical particles } \\
\text { Rough surface }\end{array}$ \\
\hline $\mathrm{C}$ & 12,500 & 9 & $7.73 \pm 3.63$ & $\begin{array}{l}\text { Spherical particles } \\
\text { Smooth surface }\end{array}$ \\
\hline
\end{tabular}

${ }^{\star}$ Isopropanol and ABS led to significant irregular shape. 


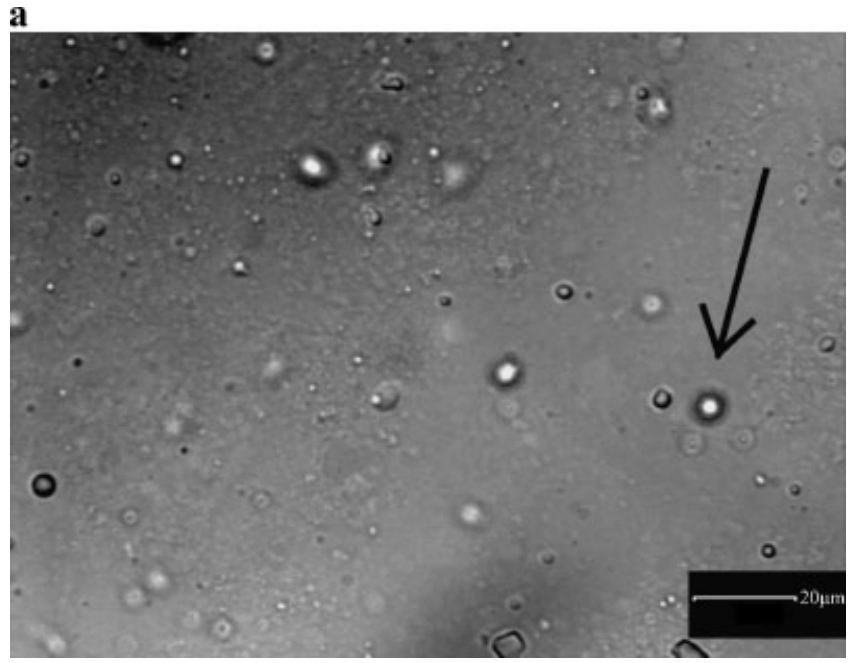

b

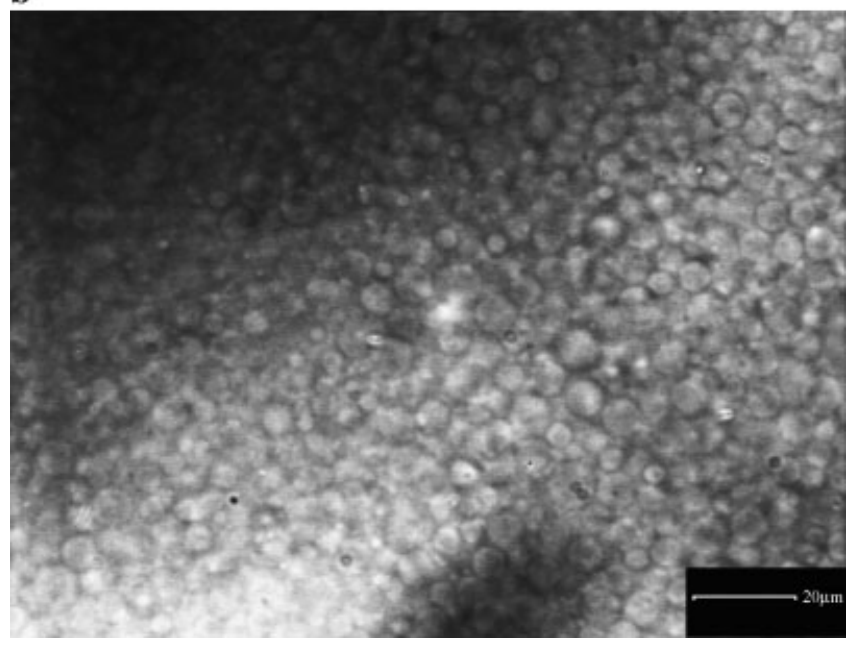

Figure 1. a: Example of oil droplets on the alginate particles. b: Photomicrograph of insulin-free alginate particles following seven wash cycles using protocol $A$.

lower ( $<7$ cycles). The association between centrifugation and dehydrating solvents decreased the number of cycles with minimal handling. The protocol with a lowest number of wash cycles was B3 with four cycles and residual oil was completely removed as seen in Figure 2 .

\section{Recovery Yield}

Important differences were found in the RY amongst the different protocols. Yield with protocol A was lower than $50 \%$ and an increase was observed $\left(\mathrm{A}_{12,500}<\mathrm{A}_{55,000}<\right.$ $\mathrm{A}_{80,000}$ ) when the centrifugation speed increased from 12,500 to $80,000 \mathrm{~g}$ as seen in Figure 3. However, differences between three groups were not statistically significant.

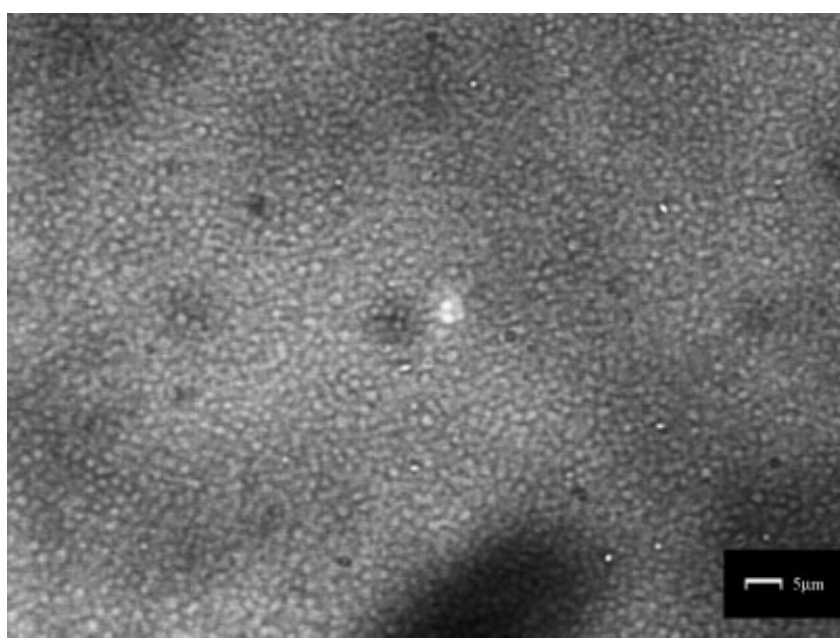

Figure 2. Protocol B3: Photomicrograph of insulin-free alginate particles following four wash cycles.

Higher centrifugation force resulted in the recovery of a larger fraction of the particles, however a careful balance is required to minimize stress on the particles or on the protein. The maintenance of the structural integrity of a therapeutic protein is essential for its efficacy in relation to physiological and pharmacological activity (Brange et al., 1992).

Concerning protocol $\mathrm{B}$ and comparing to protocol $\mathrm{A}$, a significantly higher RY was obtained using dehydrating solvents coupled with centrifugation. There were significant statistical differences between these two protocols with $P=0.0011$. Considering that the preparation takes place in an oily dispersion, the particles are more highly mobile with a low viscosity solvent such as acetone and isopropanol. An increase in RY (around 15\%-25\%) was obtained for protocols B1, B2, B3, and B4 showing that the use of isopropanol and acetone significantly increased the RY as illustrated in Figure 3. Both solvents are dehydrating and miscible with both the water present in the particles and the hydrophobic suspension medium (Arshady, 1990). Alginate particles contain high water content and due to a partition phase phenomenon, internal water is extracted, resulting in dry particles which lose affinity with the interface of the emulsion medium and readily precipitate. Moreover, the elimination of these solvents is relatively easy. Finally, either hexane or ether did not significantly modify the RY. These solvents only remove strongly bound contaminants such as residual oil as previously described (Miyazaki et al., 2003; Ramdas et al., 1999) but did not affect the RY.

Finally, protocol $\mathrm{C}$ had the same RY as protocol $\mathrm{A}_{12500}$ having no influence on the RY. The presence of surfactant led to a milky suspension followed by a difficult visualization of the particles. As a result, a considerable quantity of the particles was lost. 


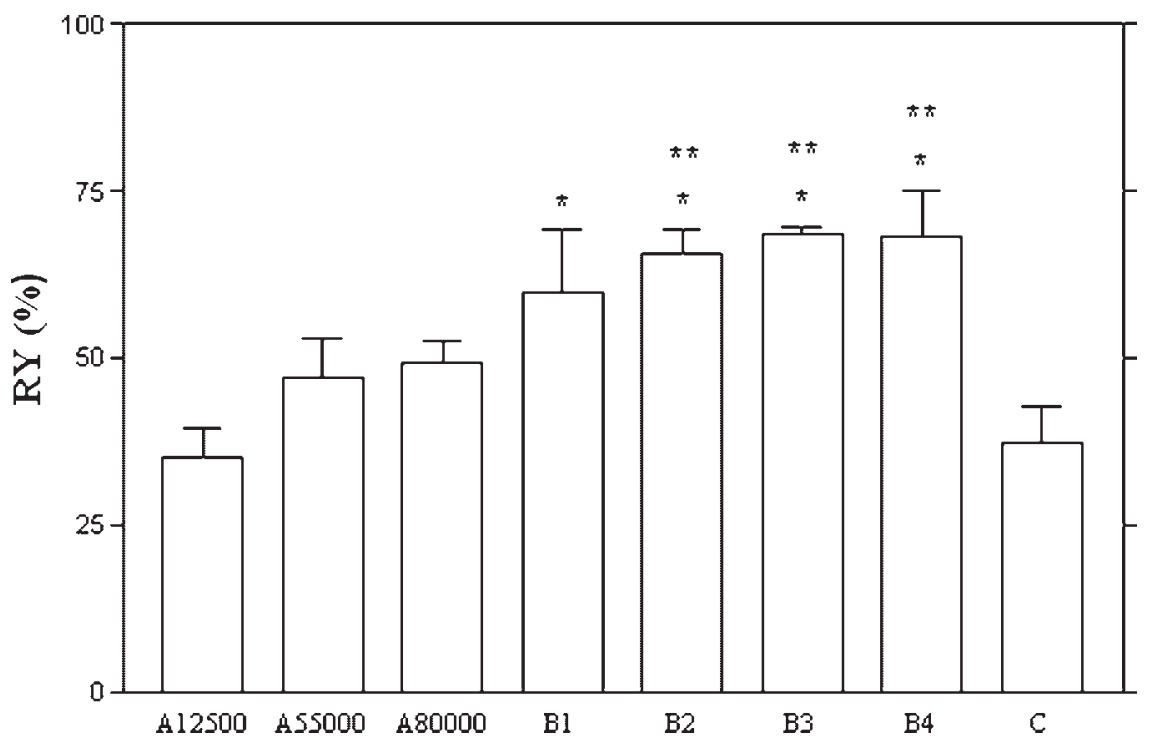

Figure 3. Influence of several recovery protocols on the recovery yield (RY) of alginate particles. Each value represents Mean $\pm S D, n=2 .{ }^{*}$ Significant differences from protocols $A_{12,500}$ and $C(P<0.05)$. ${ }^{*}$ Significant differences from protocols $A_{55,000}, A_{80,000}(P<0.05)$.

\section{Particle Size}

Small-sized insulin-loaded alginate microparticles recovered through the various protocols had mean diameters varying from $4.2 \mu \mathrm{m}$ to those forming significant agglomerates with mean diameters to $135 \mu \mathrm{m}$. In the case of protocol A, no differences were observed in terms of particle mean size with an increase of centrifugal force. In contrast, the particle mean size changed as different mixtures of solvents were applied as seen in Table II. Acetone has been applied to break nanoemulsions (Zhi et al., 2005). It is a water-miscible solvent used as a recovery agent due to its psychochemical properties and pharmaceutical acceptability with regard to toxicity (Allémann et al., 1993). However, when it is used with large volumes, particles tend to aggregate (protocol $\mathrm{B} 1$ ). When using isopropanol and acetone (protocols B2, B3, and B4), the size of the particles slightly decreased and aggregation did not occur except for B4. Isopropanol has also been used as solvent to prepare nanoparticles (Schubert and Muller-Goymann, 2003) and it has been show to influence size of alpha-Fe ultrafine particles (Wang et al., 2000). On the other hand, ether led to some agglomeration and consequently led to an increase in the mean particle diameter (protocol B4). In contrast, adding hexane (protocol B3) did not alter the mean diameter nor was aggregation observed. Hexane with low boiling point and low-toxicity is a desirable organic solvent in many applications (Chen et al., 2003). It is easily removed from the formulation due to high volatility (Chen et al., 2003), and it has also been applied in insulin bioactive formulations (Vladisavljevic and Williams, 2005). Finally, a recovery procedure involving emulsifier in a high calcium medium was also tested (protocol C) and no influence on the mean particle size was observed.

\section{Morphological Characterization}

The structure of insulin-loaded particles was examined by SEM. Photomicrographs showed that variations in recovery parameters had an important effect on particle appearance. The exclusive use of centrifugation for particle recovery did not change the spherical shape or smooth surface of the insulin-loaded alginate particles, as illustrated in Figure 4. A mixture of acetone/acetate buffer solution (B1) or acetone/ isopropanol/Tween 80/acetate buffer solution (B2) caused a significant change in particle shape and surface morphology as seen in Figure 5a and b, respectively. B3 showed relatively

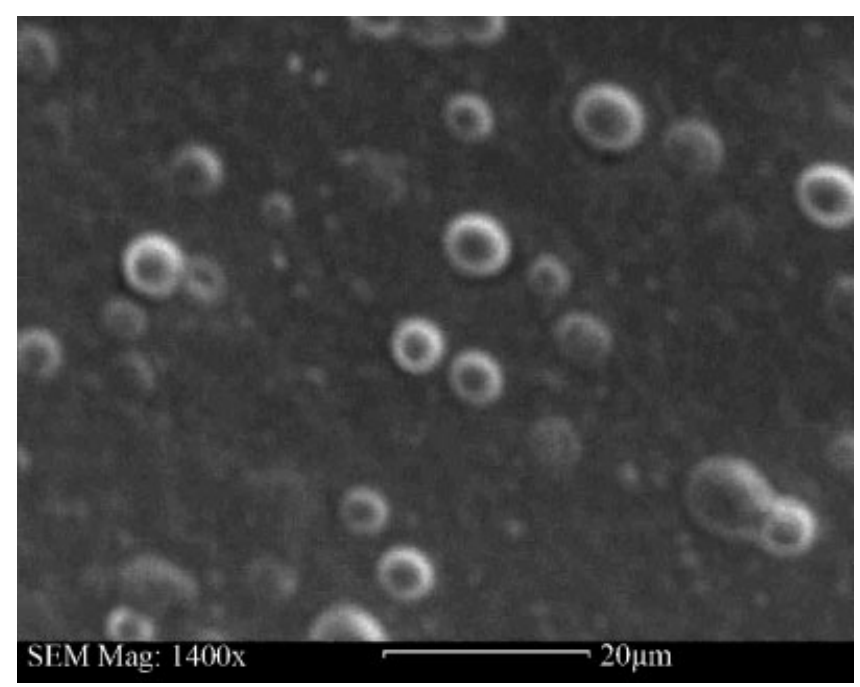

Figure 4. SEM photograph of insulin-loaded alginate particles recovered exclusively by centrifugation (magnification 1,400×) 


\section{$\mathbf{a}$}

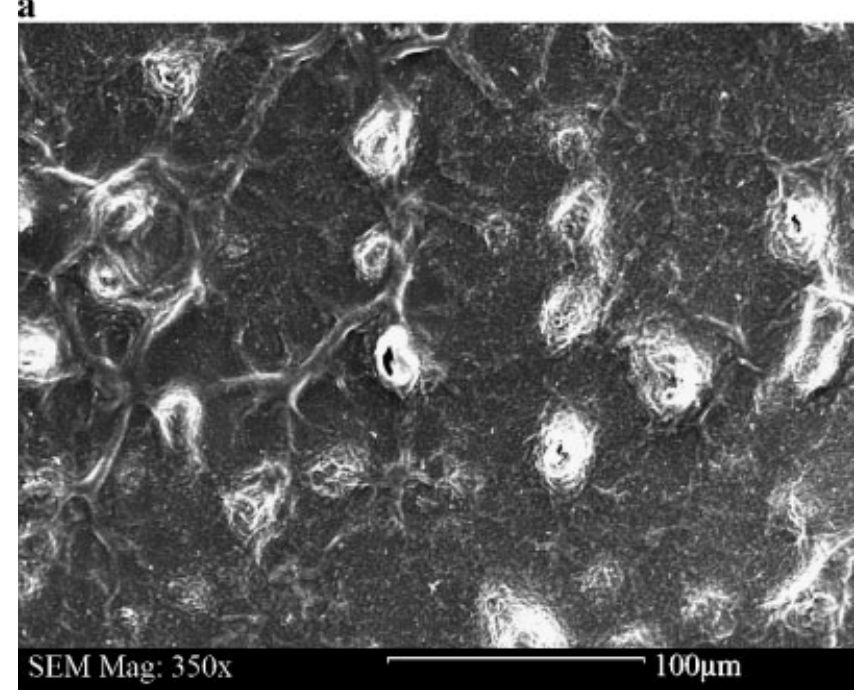

c

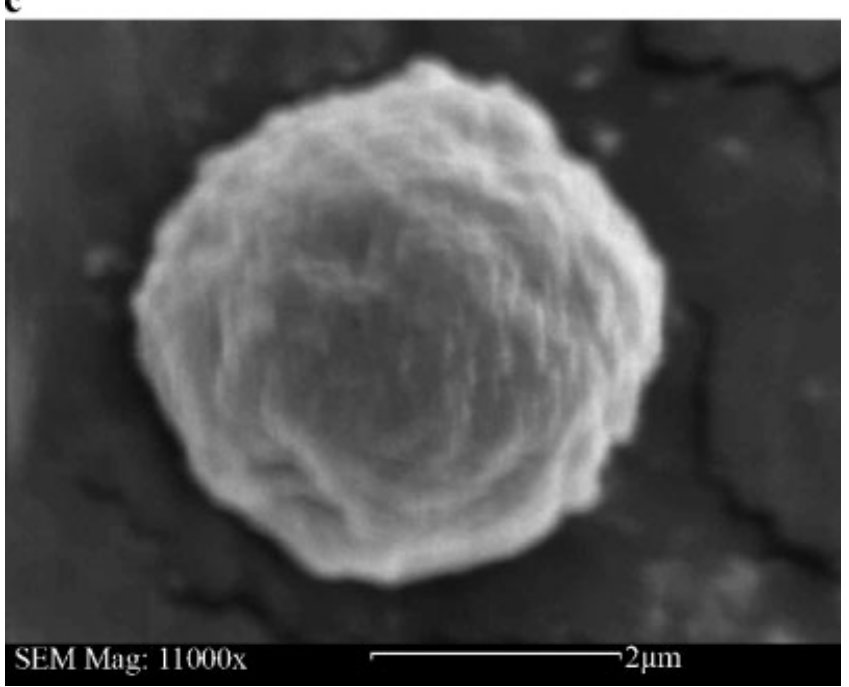

b

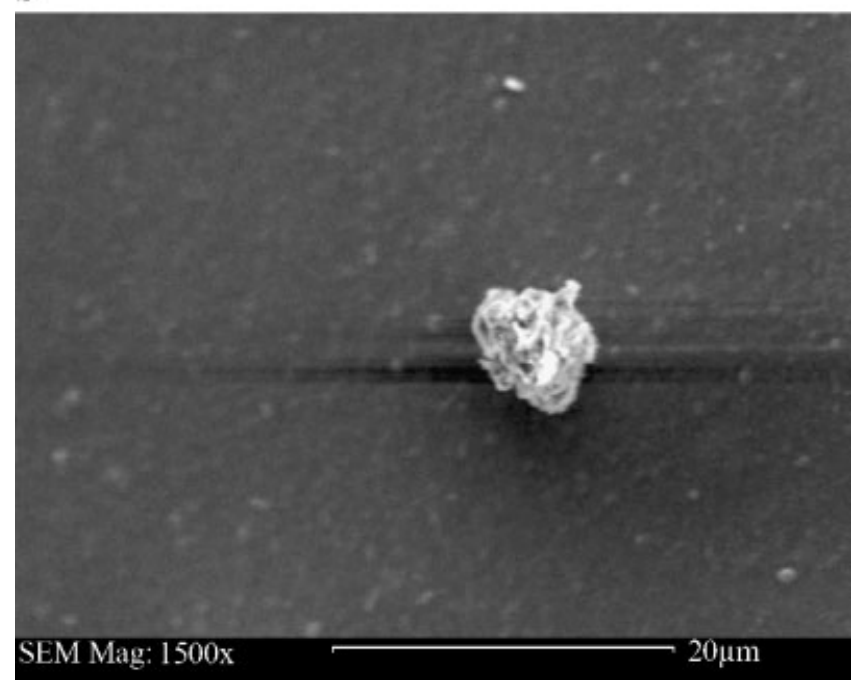

d

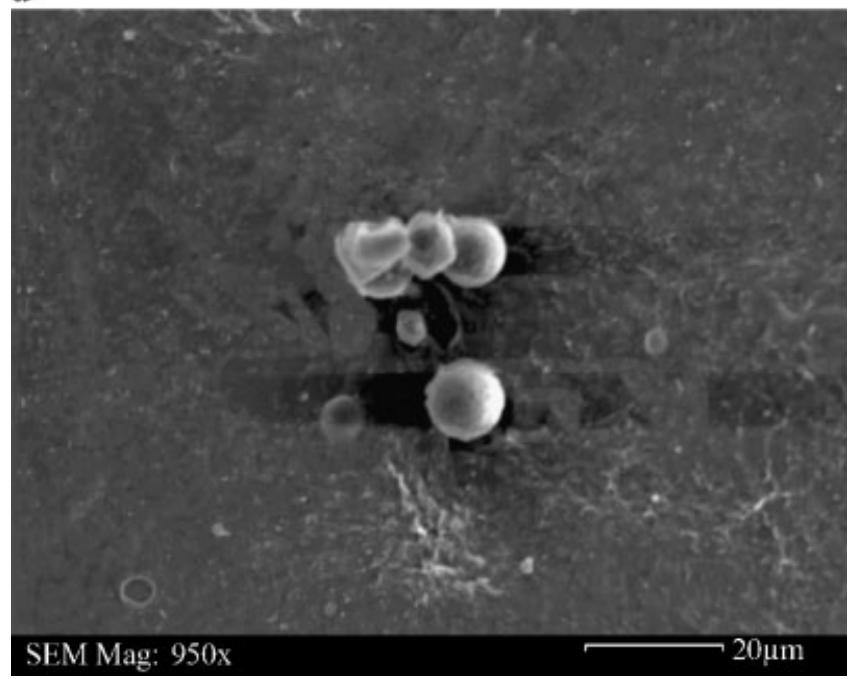

Figure 5. SEM photographs of insulin-loaded alginate particles recovered through protocols B1 (a, magnification $350 \times$ ), B2 (b, magnification 1,500 $\times$ ), B3 (c, magnification $11,000 \times$ ), and small agglomerate of B4 (d, magnification $950 \times$ ).

uniform and spherical particles, but with a rough surface as demonstrated in Figure $5 \mathrm{c}$. The roughness was once more due to use of dehydrating solvents. Water extraction appears to change the alginate network. Also, protocol B4 partially maintains the particle spherical shape and also led to a rough particle surface as illustrated in Figure 5d. Protocol C produced particles with good sphericity and smooth surface as shown in Figure 6. The smooth and dense particle surface could be due to residual surfactants, as observed previously (Magenheim and Benita, 1991).

\section{Insulin Encapsulation Efficiency}

Centrifugal force had some influence on encapsulation efficiency as shown in Figure 7. In contrast, the encapsula- tion efficiency with protocols $\mathrm{B}$ and $\mathrm{C}$ changed considerably from B2 (acetone, isopropanol, Tween 80, and acetate buffer solution) $<$ B1 (acetone and acetate buffer solution) $<$ C (calcium chloride and Tween 80) $<$ B4 (acetone, isopropanol, ether, and acetate buffer solution) $<$ B3 (acetone, isopropanol, hexane, and acetate buffer solution). Between B3 and B2, there was a significant statistical difference ( $P=0.0365$ ). Compared to protocol A, the efficiency values of protocol B could be explained by several factors. The number of wash cycles with protocol B was lower than protocol A which can suggest less protein losses. As well, the alginate surface was strongly modified. A rough surface could be responsible for the small loss of protein during washing and explain the higher encapsulation efficiencies compared to protocol A. As well, it may be possible that 


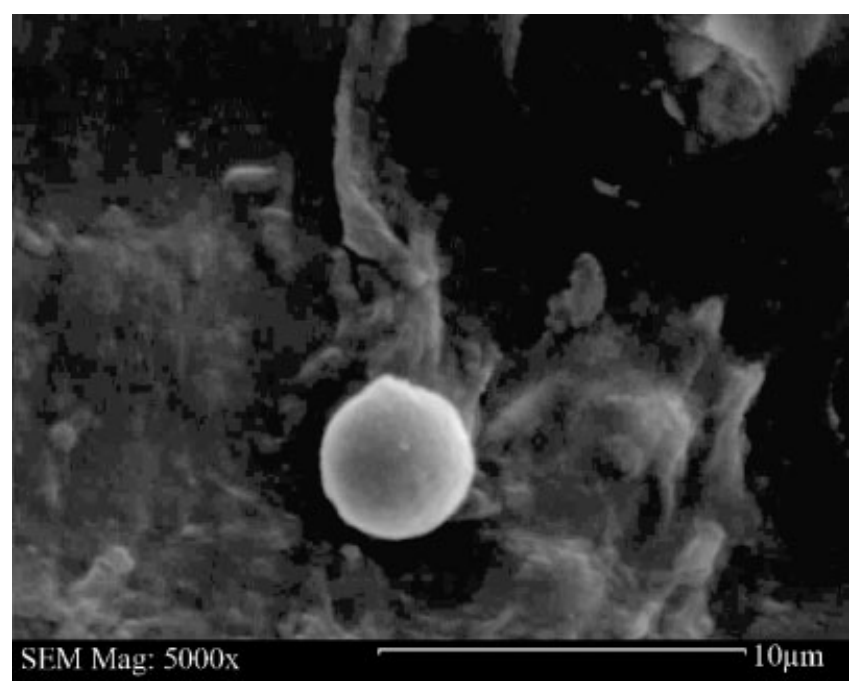

Figure 6. SEM photomicrograph of insulin-loaded alginate particles recovered through protocol C (magnification $5,000 \times$ ).

dehydrating solvents alter alginate permeability. However, the volume of dehydrating solvents had a significant influence on this parameter. During washing, insulin may be drawn out of the particles following the extracted water. Thus the balance between insulin retention and water extraction must be considered. In fact, high amounts of acetone $(40 \mathrm{~mL}$ for $\mathrm{B} 1$ and $30 \mathrm{~mL}$ for $\mathrm{B} 2)$ caused some diffusive loss of encapsulated insulin, and the mixture of $30 \mathrm{~mL}$ of acetone and $10 \mathrm{~mL}$ of isopropanol led to higher insulin diffusive loss compared to $40 \mathrm{~mL}$ of acetone. By reducing the volume of acetone to $15 \mathrm{~mL}$ (B3 and $\mathrm{B} 4$ ), the encapsulation yield slightly increased. The more suitable protocol was B3 with highest encapsulation efficiency. As well, the presence of calcium in the washing medium in protocol $\mathrm{C}$ also led to higher encapsulation efficiency. Structurally, calcium ions interact with alginate residues within alginate electronegative cavities (Braccini and Perez, 2001). Higher calcium levels in the medium may have led to additional cross-reaction between the interchain $\mathrm{COO}^{-}$ groups. Calcium chloride has been applied in order to reduce particle swelling and the resulting diffusive loss of the encapsulant (Vandenberg et al., 2001). Consequently, inclusion of $\mathrm{CaCl}_{2}$ in the washing medium could be desirable to preserve the alginate gel network. Lastly, all recovery strategies to isolate particles were performed by using acetate buffer at $\mathrm{pH} 4.5$ as washing medium. In fact, the washing medium $\mathrm{pH}$ is an important factor for proteinpolymer interaction and consequently, encapsulation efficiency. At $\mathrm{pH} 4.5$, the interactions between alginate and insulin are very favorable since they were oppositely charged ( $\mathrm{pI}$ of insulin $~ 5.3$ (Chien, 1996) and alginate $\mathrm{pK}$ 3.38 and 3.65 for $M$ and $G$ residues, respectively, Draget et al., 1994). As well, the intrinsic nature of this emulsification-based methodology and the high hydrophilic nature of the protein could also explain the resultant encapsulation efficiencies.

\section{Release Profile}

Figure 8 depicts release profiles of insulin from particles under simulated gastric and intestinal conditions. At low gastric $\mathrm{pH}$, insulin was rapidly released from tested formulations (burst release around $100 \%$ at $5 \mathrm{~min}$ ) probably due to rapid ion-exchange $\left(\mathrm{H}^{+}\right.$and $\left.\mathrm{Ca}^{2+}\right)$. No significant

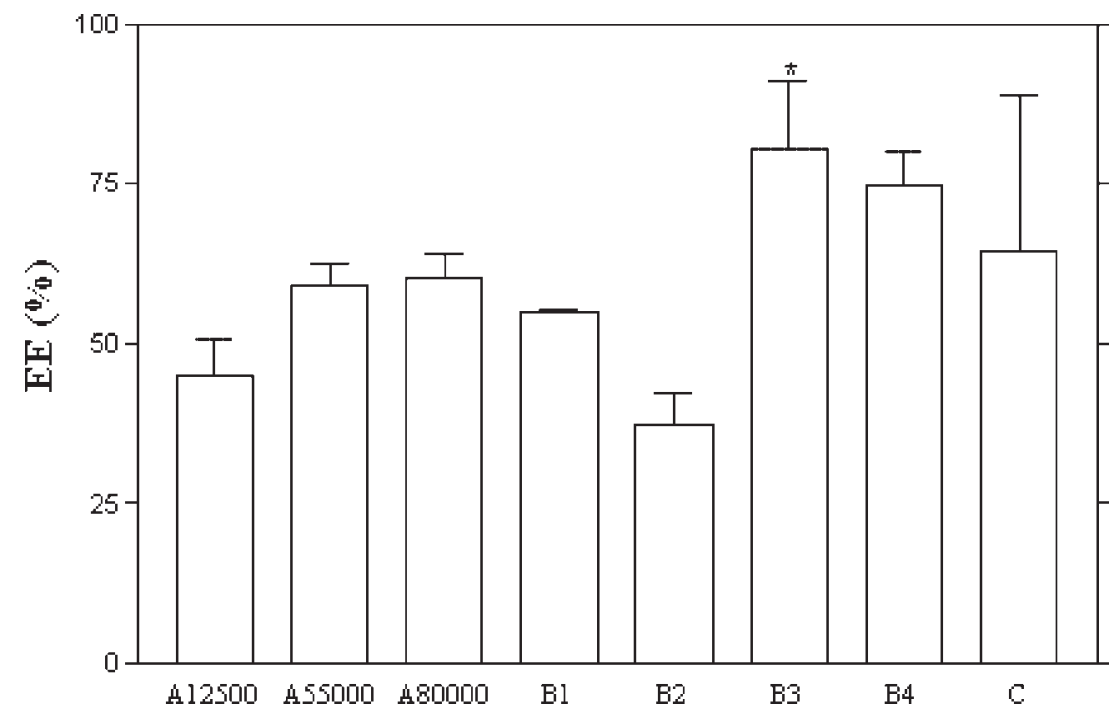

Figure 7. Influence of recovery protocols on the encapsulation efficiency of insulin-loaded alginate particles. Each value represents $M e a n \pm$ SD, $n=3$. ${ }^{*}$ Significant differences from B2 $(P<0.05)$. 


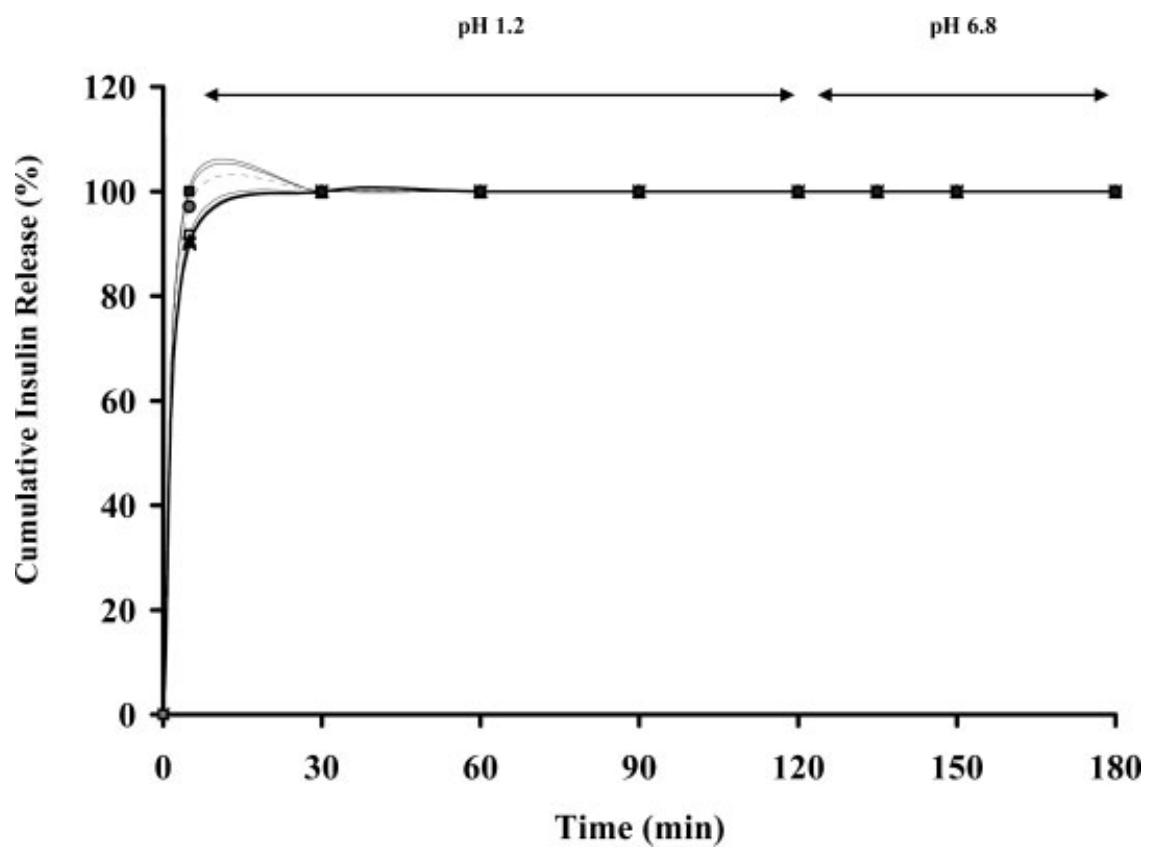

Figure 8. Release profiles of insulin alginate particles (protocols A (-), B1 (- $\square-)$, B2 (- $\mathbf{\Delta}-)$, B3 (-x-), B4 (-- $\bigcirc--)$, and C (- - -) at two different pH conditions depending on time. Experiments were performed in hydrochloric acid at $\mathrm{pH} 1.2$ followed phosphate buffer at $\mathrm{pH} 6.8$.

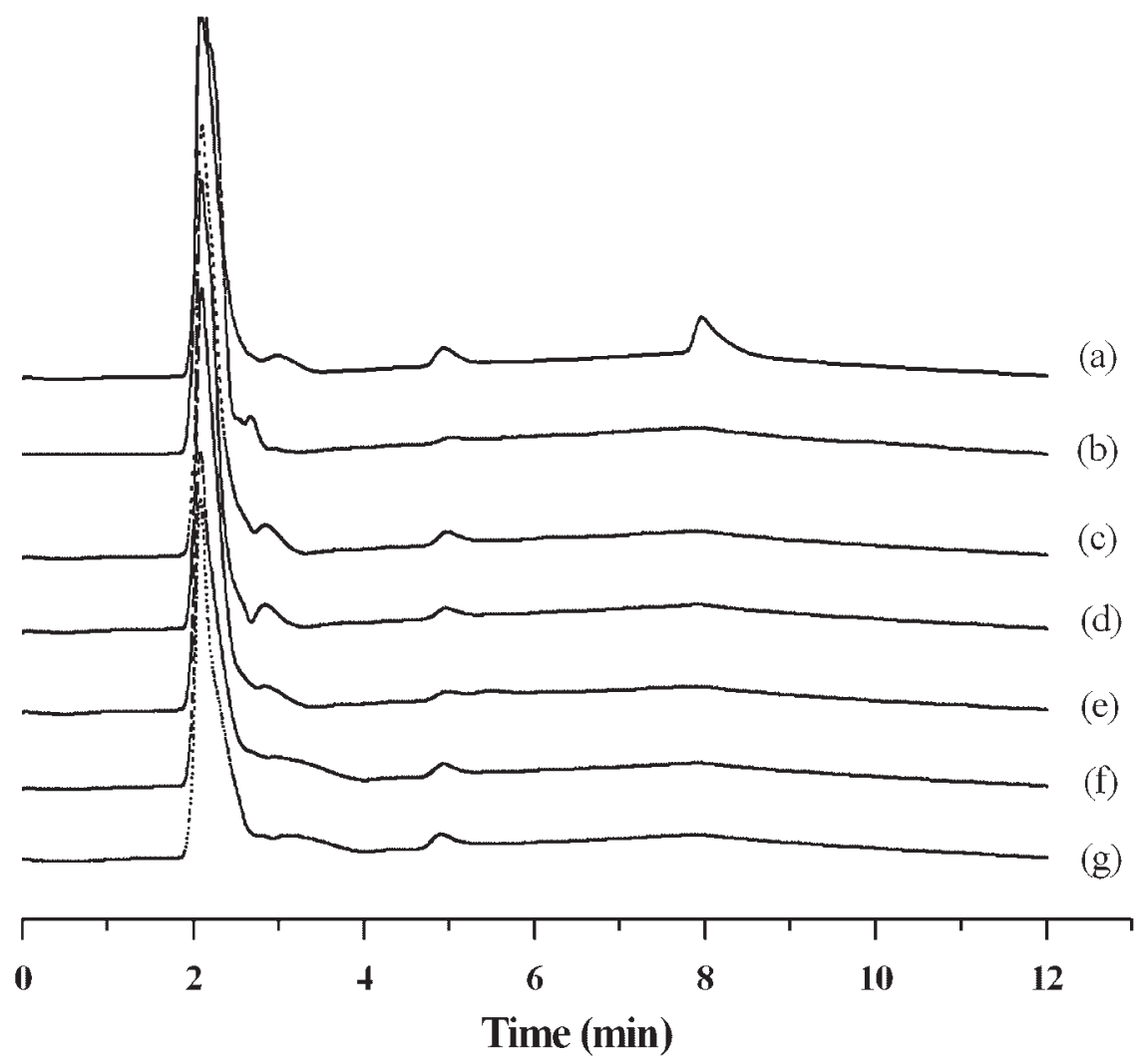

Figure 9. Reverse phase HPLC chromatographs of a reference solution of insulin samples (a) and the insulin obtained from alginate particle dissolution: protocols A (b), B1 (c), B2 (d), B3 (e), B4 (f), and C (g). Measurements were run in triplicate with good reproducibility though only graphs of one experiment are presented. 
a

RT: $0.00-11.98$ SM: $7 B$

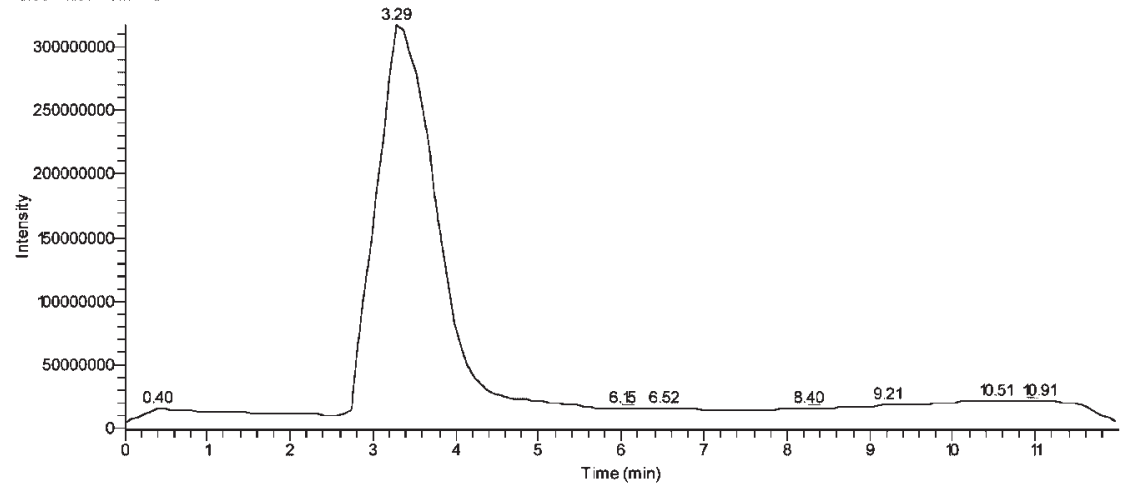

RT: 3.29 AV: 1 NL: $6.60 \mathrm{E} 6$ F: + c ESI Full ms [ 50.00-2000.00]

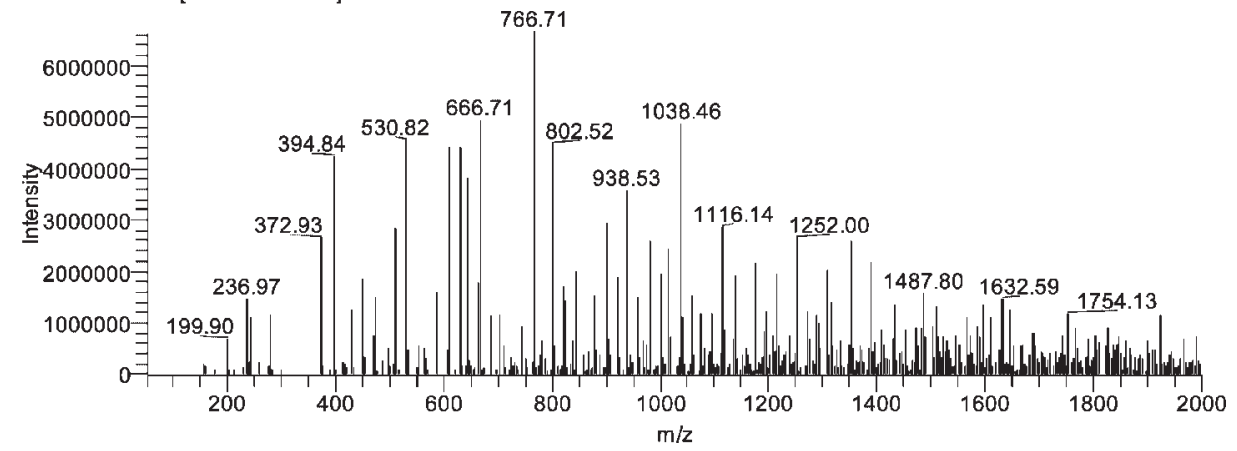

b

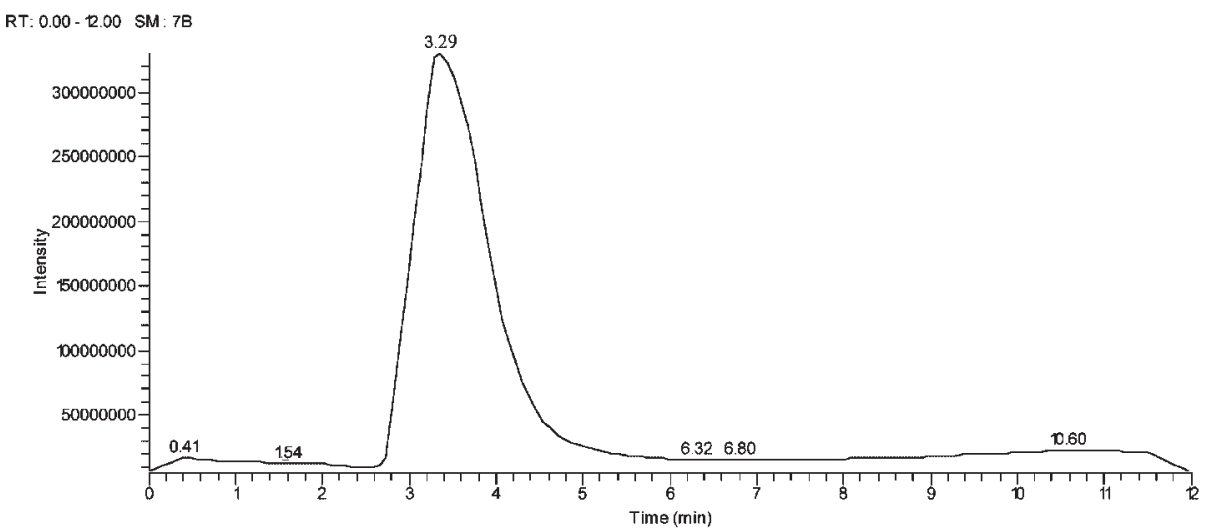

RT: 3.29 AV: 1 NL: 6.15E6 F: + c ESI Full ms [ 50.00-2000.00]

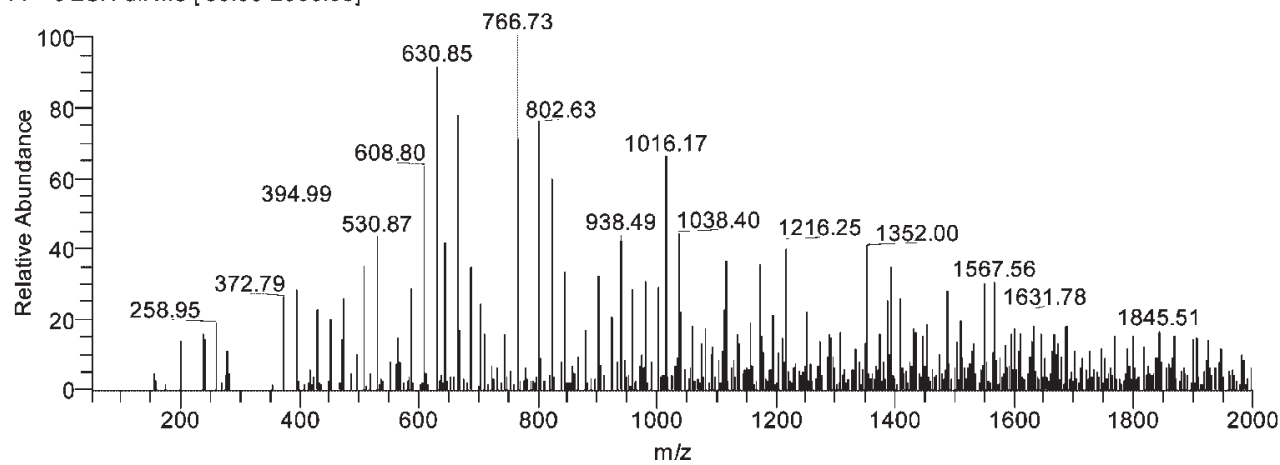

Figure 10. HPLC-Mass representative chromatograph of a reference solution of insulin sample (a) and an example of chromatogram of insulin obtained from alginate particle dissolution obtained by recovery tested protocols (b).

986

Biotechnology and Bioengineering, Vol. 96, No. 5, April 1, 2007

DOL $10.1002 /$ bit 
differences were observed for each protocol. The value of insulin released was constant even after changing the medium to near neutral conditions. This fact may suggest the co-existence of simultaneous mechanisms. pH-dependent insulin release as well as alginate porosity may have a significant influence on the insulin release profile. There are many parameters that are used to control the release rate of drug from polymeric drug carrier systems. Ongoing research will developed strategies to obtain controlled insulin release profile.

\section{RP-HPLC and HPLC-MS Analysis}

Maintaining protein stability and minimizing aggregate formation during processing is critical in providing safe and efficacious protein therapeutics with long shelf lives. Insulin consists of 51 amino acids with a molecular weight of 5,800 $\mathrm{g} / \mathrm{mol}$ and degrades rapidly in acid medium at Asn 21, while in slightly acid or alkaline medium deamination takes place at residue Asn B3 (Oliva et al., 2000). Two techniques were applied to determine the stability of insulin: RP-HPLC and HPLC-Mass. A shift of the retention time of insulin on RPHPLC chromatogram is an indication of insulin aggregation. A freshly prepared insulin solution had a retention time of $4.8 \mathrm{~min}$. The chromatogram obtained by insulin released from alginate particles highlighted a single peak identical to that of a reference solution of insulin. The same retention time was obtained for all formulations indicating that insulin was preserved during the particle manufacture and recovery as shown in Figure 9. The HPLC-Mass chromatograms of reference insulin solution and insulin released from alginate particles were similar as shown in Figure 10a and b. HPLC-MS analysis showed that no high molecular weight transformation products were formed.

\section{Secondary Structure of Insulin Released}

Preservation of the structural integrity of a protein drug after release is crucial for its biological efficacy. Thus, the secondary structure of insulin released from particles was investigated using CD. Figure 11 shows the far UV CD spectra of the diluted solutions of insulin released from alginate particles and recovered by various protocols and one diluted insulin reference solution (insulin nonencapsulated). The CD spectrum of insulin non-encapsulated in PBS, at pH 7.4, shows two minima at 209 and 224 $\mathrm{nm}$. These results were in close agreement with results presented by other studies (Tiyaboonchai et al., 2003). There was minor deviation of the negative maximum at about 216 $\mathrm{nm}$ for protocol A. Protocols B1, B2, B4, and C produced similar spectra nevertheless they were different from the reference solution especially with attenuated second minimum. The secondary structure for insulin (native conformation) may have slightly changed after encapsulation and recovery processes by protocols A, B1, B2, B4, and C. A possible explanation is that insulin could be linked to
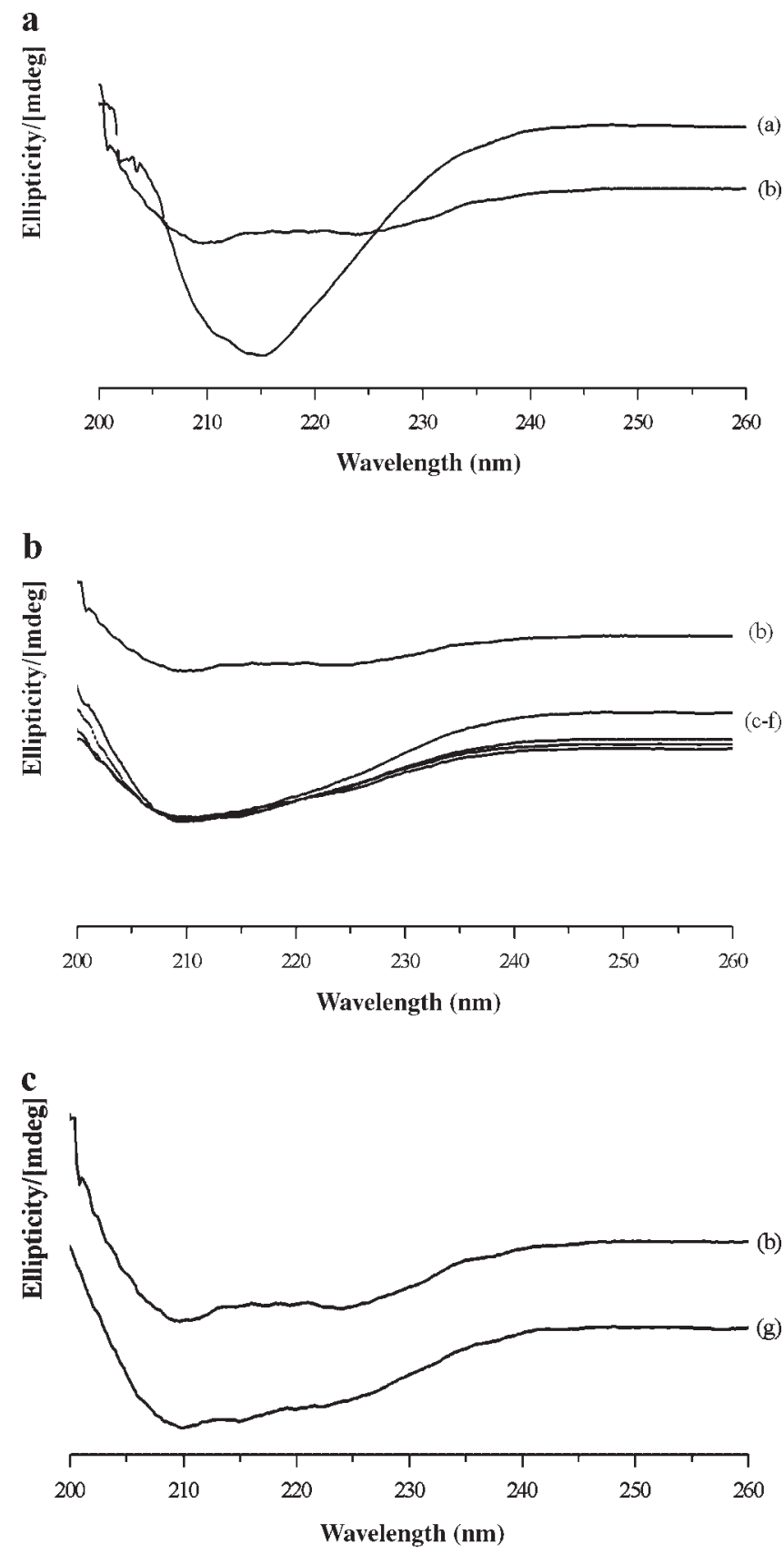

Figure 11. Effect of various recovery protocols on the CD spectra of insulin in solution $(10 \mu \mathrm{M})$ and insulin released from nanospheres formulated $(10 \mu \mathrm{M})$ in PBS at 7.4 and $25^{\circ} \mathrm{C}$ : (a) protocol $\mathrm{A}$, (b) insulin non-encapsulated (reference solution), (c-f) protocols B1, B2, B4, and C, and (g) protocol B3.

alginate polymer altering protein structure, though not representing denaturation or loss of insulin activity. Finally, different CD data were observed for protocol B3. The features of the spectra for reference solution and protocol B3 were similar, and indicated that insulin recovered from alginate particles using protocol B3, after $2 \mathrm{~h}$ of contact in PBS, retained its secondary structure. 


\section{Conclusions}

Insulin-loaded alginate microparticles with small size were successfully prepared by an emulsification method using internal gelation technology. The recovery step is problematic, and thus centrifugation coupled with dehydrating solvents was applied to improve RY and insulin encapsulation efficiency (protocol B). The presence of solvents also enables particle recovery at lower centrifugal force. Acetatebuffer-acetone-isopropanol-hexane coupled with lower speed rate of centrifugation decreased the size of the particles, and increased the RY and the encapsulation efficiency of insulin, but the morphology of insulin-loaded alginate particles was slightly altered. The secondary structure of insulin was also tested after encapsulation and no effects on secondary structure were seen for insulin after encapsulation and recovery process by protocol B3. This methodology of producing microparticles was gentle for insulin and potentially other proteins, as seen by RP-HPLC /HPLC-Mass and CD analysis, and is easily manipulated with important application to the pharmaceutical field. Results describing the biological activity of released insulin will be the subject of published work in the near future.

The authors also gratefully acknowledge Dr. Margarida Figueiredo and Eng. Vítor Redondo from Labgran, Coimbra, Portugal for their skillful technological support for LDS, Dr. Vítor Madeira e Dr. Manuel Matos from FCTUC for help with the centrifugation studies, Dr. Alexandra Rocha Gonsalves from FCTUC for her assistance with HPLC-mass assays, and finally, Dr. João Pessoa from ISTUTL for his kind support on CD.

\section{References}

Alexakis T, Boadi DK, Quong D, Groboillot A, O’Neill I, Poncelet D, Neufeld RJ. 1995. Microencapsulation of DNA within alginate microspheres and cross-linked chitosan membranes for in vivo application. Appl Biochem Biotechnol 50:93-106.

Allémann E, Doelker E, Gurny R. 1993. Drug loaded Poly(lactic acid) nanoparticles produced by a reversible salting-out process: Purification of an injectable dosage form. Eur J Pharm Biopharm 39:13-18.

Arshady R. 1990. Albumin microspheres and microcapsules: Methodology of manufacturing techniques. J Control Rel 14:111-131.

Braccini I, Perez S. 2001. Molecular basis of $\mathrm{Ca}^{2+}$-induced gelation in alginates and pectins: The egg-box model revisited. Biomacromolecules 2:1089-1096.

Brange J, Havelund S, Hougaard P. 1992. Chemical stability of insulin 2. Formation of higher molecular weight transformation products during storage of pharmaceutical preparations. Pharm Res 9:727-734.

Carino GP, Jacob JS, Mathiowitz E. 2000. Nanosphere based oral insulin delivery. J Control Release 65:261-269.

Chen F, Xu G-Q, Hor TSA. 2003. Preparation and assembly of colloidal gold nanoparticles in CTAB-stabilized reverse microemulsion. Mat Let 57:3282-3286.

Chien YW. 1996. Human insulin: Basic sciences to therapeutic uses. Drug Dev Ind Pharm 22:753-789.

Cho N-H, Seong S-Y, Chun K-H, Kim Y-H, Kwon IC, Ahn B-Y, Jeong SY. 1998. Novel mucosal immunization with polysaccharide-protein conjugates entrapped in alginate microspheres. J Control Rel 53:215-224.
Draget KI, Skjak Braek G, Smidsrod O. 1994. Alginic acid gels: The effect of alginate chemical composition and molecular weight. Carbohydr Polym 25:31-38.

Ma Z, Lim TM, Lim L-Y. 2005. Pharmacological activity of peroral chitosaninsulin nanoparticles in diabetic rats. Int J Pharm 293:271-280.

Magenheim B, Benita S. 1991. Nanoparticle characterization: A comprehensive physicochemical approach. STP Pharm Sci 1:221-241.

Mesiha MS, Sidhom MB, Fasipe B. 2005. Oral and subcutaneous absorption of insulin poly(isobutylcyanoacrylate) nanoparticles. Int J Pharm 288:289-293.

Miyazaki Y, Yakou S, Nagai T, Takayama K. 2003. Release profiles of theophylline from microspheres consisting of dextran derivatives and cellulose acetate butyrate: Effect of polyion complex formation. Drug Dev Ind Pharm 29:795-804.

Morishita M, Goto T, Peppas NA, Joseph JI, Torjman MC, Munsick C, Nakamura K, Yamagata T, Takayama K, Lowman AM. 2004. Mucosal insulin delivery systems based on complexation polymer hydrogels: Effect of particle size on insulin enteral absorption. J Control Rel 97:115-124

Norris DA, Puri N, Sinko PJ. 1998. Effect of physical barriers and properties on the oral absorption of particulates. Adv Drug Deliv Rev 34:135-154.

Oliva A, Farina J, Llabres M. 2000. Development of two high-performance liquid chromatographic methods for the analysis and characterization of insulin and its degradation products in pharmaceutical preparations. J Chromatogr B 749:25-34.

Poncelet D. 2001. Production of alginate beads by emulsification/internal gelation. Ann NY Acad Sci 944:74-82.

Poncelet D, Lencki R, Beaulieu C, Halle JP, Neufeld RJ, Fournier A. 1992. Production of alginate beads by emulsification/internal gelation. I. Methodology. Appl Microbiol Biotechnol 38:39-45.

Poncelet D, Smet BPD, Beaulieu C, Huguet ML, Fournier A, Neufeld RJ. 1995. Production of alginate beads by emulsification/internal gelation. II. Physicochemistry. Appl Microbiol Biotechnol 43:644-650.

Poncelet D, Babak V, Dulieu C, Picot A. 1999. A Physico-chemical approach to production of alginate beads by emulsification-internal ionotropic gelation. Colloids Surf A: Physiochem Eng Aspects 155:171-176.

Quong D, Neufeld RJ, Skjak-Braek G, Poncelet D. 1998. External versus internal source of calcium during the gelation of alginate beads for DNA encapsulation. Biotechnol Bioeng 57:438-446.

Ramdas M, Dileep KJ, Anitha Y, Paul W, Sharma CP. 1999. Alginate encapsulated bioadhesive chitosan microspheres for intestinal drug delivery. J Biomater Appl 13:290-6.

Reis CP, Neufeld RJ, Ribeiro AJ, Veiga F. 2006. Design of insulin-loaded alginate nanoparticles: Influence of calcium ion on polymer gel matrix properties. Chem Ind Chem Eng Quart 12:47-52.

Ribeiro AJ, Neufeld RJ, Arnaud P, Chaumeil JC. 1999. Microencapsulation of lipophilic drugs in chitosan-coated alginate microspheres. Int J Pharm 187:115-123.

Saez A, Guzman M, Molpeceres J, Aberturas MR. 2000. Freeze-drying of polycaprolactone and poly(d,l-lactic-glycolic) nanoparticles induce minor particle size changes affecting the oral pharmacokinetics of loaded drugs. Eur J Pharm Biopharm 50:379-387.

Sakuma S, Hayashi M, Akashi M. 2001. Design of nanoparticles composed of graft copolymers for oral peptide delivery. Adv Drug Deliv Rev 47:21-37.

Schubert MA, Muller-Goymann CC. 2003. Solvent injection as a new approach for manufacturing lipid nanoparticles-evaluation of a method and process parameters. Eur J Pharm Biopharm 55:125-131.

Soppimath KS, Aminabhavi TM, Kulkarni AR, Rudzinski WE. 2001. Biodegradable polymeric nanoparticles as drug delivery devices. J Control Rel 70:1-20.

Takeuchi H, Yamamoto H, Niwa T, Hino T, Kawashima Y. 1996. Enteral absorption of insulin in rats from mucoadhesive chitosan-coated liposomes. Pharm Res 13:896-901.

Tiyaboonchai W, Woiszwillo J, Sims RC, Middaugh CR. 2003. Insulin containing polyethylenimine-dextran sulfate nanoparticles. Int J Pharm 255:139-151. 
Vandenberg GW, Drolet C, Scott SL, Noue Jdl. 2001. Factors affecting protein release from alginate-chitosan coacervate microcapsules during production and gastric/intestinal simulation. J Control Rel 77:297307.

Vladisavljevic GT, Williams RA. 2005. Recent developments in manufacturing emulsions and particulate products using membranes. Adv Col Int Sci 113:1-20.
Wang CY, Jiqng WQ, Zhou Y, Wang YN, Chen ZY. 2000. Synthesis of [alpha]-Fe ultrafine particles in a saturated salt solution/isopropanol/ PVP microemulsion and their structural characterization. Mat Res Bull 35:53-58.

Zhi J, Wang Y, Luo G. 2005. Adsorption of diuretic furosemide onto chitosan nanoparticles prepared with a water-in-oil nanoemulsion system. React Func Polym 65:249-257. 